\title{
Eating Disorder Pathology in Adolescents Participating in a Lifestyle Intervention for Obesity: Associations with Weight Change, General Psychopathology and Health-Related Quality of Life
}

\author{
Katrin E. Giel ${ }^{a}$ Stephan Zipfel ${ }^{a} \quad$ Roland Schweizer ${ }^{b}$ Regina Braun ${ }^{b}$ \\ Michael B. Ranke ${ }^{b}$ Gerhard Binder ${ }^{b}$ Stefan Ehehalt ${ }^{c}$ \\ for the DISKUS Study Group \\ a Department of Psychosomatic Medicine and Psychotherapy, Medical University Hospital \\ Tübingen, 'b Pediatric Endocrinology and Diabetes, University Children's Hospital Tübingen, \\ Tübingen, ' Public Health Department, Child and Adolescent Health, Stuttgart, Germany
}

Key Words

Adolescent $\cdot$ Eating disorder · Obesity $\cdot$ Weight loss

\begin{abstract}
Objective: The aim of this study was to identify the prevalence of eating disorder symptoms in obese adolescents participating in a lifestyle intervention for weight loss and to investigate possible relationships with weight change, general psychopathology, and health-related quality of life (HRQOL). Method: At the beginning and after completion of a 6-month lifestyle intervention, 41 participants (20 females; age: $13.7 \pm 1.4$ years) reported on core symptoms of eating disorders (SCOFF), self-esteem (Rosenberg Self-Esteem Scale, RSES), and HRQOL (Questionnaire for Measuring Health-Related Quality of Life in Children and Adolescents, KINDL), while parents filled in a questionnaire assessing their children's internalizing and externalizing behavioral problems (Child Behavior Checklist, CBCL). Results: Compared to agematched normative samples, patients showed increased behavior problems and an impaired HRQOL. $43 \%$ of the patients were screened positive for an eating disorder pathology, and this subgroup showed an increased psychopathological burden compared to patients that were screened negative. The lifestyle intervention resulted in a significant weight loss which was unaffected by the presence of an eating disorder pathology. The screening rate for eating disorders remained stable after the intervention. Conclusion: The large overlap, mutual interaction, and high burden of eating and weight problems in children and adolescents underpin the need for an integrated view in both prevention and treatment approaches in pediatric obesity.


Giel et al.: Eating Disorder Pathology in Adolescents Participating in a Lifestyle Intervention for Obesity: Associations with Weight Change, General Psychopathology ...

\section{Introduction}

Behavioral lifestyle interventions are efficient treatment strategies for weight loss in most children and adolescents, as assessed by a recent Cochrane review [1]. However, the authors of this review also point out that more knowledge on psychosocial contributions to weight change in children and adolescents is needed in order to improve treatment and to develop tailored interventions [1].

The possibly most intensely studied psychosocial factors in pediatric obesity research are health-related quality of life (HRQOL) and self-esteem [1, 2]. HRQOL refers to an individual's well-being associated with physical, mental, and social functioning [2], while self-esteem covers a sense of competence and self-worth and is sometimes conceptualized as a subcomponent of HRQOL [3]. Comparable to evidence in obese adults (see [4] for a review), there is consistent evidence that obese children and adolescents report poorer HRQOL and lower selfesteem than their normal-weight contemporaries [2,3]. Recent literature reviews suggest that, comparable to findings in adult samples [4], weight loss after targeted interventions results in an improvement of HRQOL in pediatric patients [2] and might as well have positive effects on self-esteem $[3,5]$.

A psychosocial factor that has received less attention in the research of obesity among children and adolescents is eating disorder pathology. This is surprising as a significant co-occurrence of eating and weight disorders is well-documented in adult samples [6, 7]. Evidence from cross-sectional studies suggests that, similarly as in adults, overweight and obesity in adolescence is associated with higher rates of eating disorder pathology [8], including disordered eating behaviors such as emotional eating and loss of control (LOC) over eating [9] and, to a minor degree, full-syndrome eating disorders $[8,10]$, as well as weight and shape concerns [11]. Eating disorder pathology in both normal-weight and overweight/ obese youth was associated with negative psychosocial outcomes, including emotional problems [12], externalizing and internalizing behavioral problems [13], lower self-esteem [10], and depressive symptoms [14]. Moreover, adolescence and early adulthood is the time of first onset of full-syndrome eating disorders [15], and early eating disorder pathology may predict their onset $[16,17]$. Only few studies have investigated the role of eating disorder pathology concerning weight change in pediatric samples $[18,19]$. Braet [18] reports that patients aged between 7 and 17 years who had higher total scores in an expert interview assessing eating disorder pathology lost less weight in a 2-year follow-up after a 10-month inpatient weight loss intervention. In a regression model predicting weight loss in patients aged between 8 and 18 years receiving a 10-month inpatient weight loss intervention, a compound measure of self-reported and expert-rated eating disorder pathology predicted a total variance of weight loss of $6 \%$ as assessed 4 months after the intervention had started [19].

On the whole, eating disorder pathology in children and adolescents is not only associated with further psychopathology but is also a putative barrier to successful weight change and therefore a maintaining factor of overweight $[8,20]$. Mutual interactions between selfesteem, HRQOL, general psychopathology, weight, and eating problems are probable, e.g., a low self-esteem might trigger weight concerns which may result in inappropriate weight control behaviors, leading to overweight [10].

There is a scarcity of studies investigating eating disorder pathology in pediatric samples with obesity, and particularly longitudinal data on the relationship and development of eating disorder pathology and weight change are lacking. In the present study, we conducted a 6-month lifestyle intervention program for obese adolescents investigating weight change and a range of psychosocial variables. Our aim was to identify the prevalence of eating disorder symptoms in study participants, including pathogenic weight-control behaviors, 
Giel et al.: Eating Disorder Pathology in Adolescents Participating in a Lifestyle Intervention for Obesity: Associations with Weight Change, General Psychopathology ...

Table 1. Baseline characteristics of the study sample

\begin{tabular}{ll}
\hline & Mean \pm SD \\
\hline Age, years & $13.7 \pm 1.4$ \\
BMI-SDS $_{\text {LMS }}$ & $2.2 \pm 0.4$ \\
Total quality of life $^{\mathrm{a}}$ & $68.7 \pm 11.6$ \\
Self-esteem $^{\mathrm{b}}$ & $2.6 \pm 0.5$ \\
Internalizing problems $^{\mathrm{c}}$ & $62.4 \pm 10.2$ \\
Externalizing problems $^{\mathrm{c}}$ & $56.4 \pm 10.2$ \\
Total problem score $^{\mathrm{c}}$ & $60.6 \pm 9.8$ \\
\hline
\end{tabular}

${ }^{a}$ Assessed by the KINDL. ${ }^{b}$ Assessed by the RSES. ${ }^{c}$ Assessed by the CBCL.

LOC overeating, rapid weight loss, body image disturbance, and preoccupation with food, and to investigate possible relationships of these symptoms with weight change, general psychopathology, and HRQOL.

We hypothesized that (i) there would be a subgroup of patients exhibiting symptoms of an eating disorder and that these patients would (ii) report lower HRQOL, (iii) report lower self-esteem, (iv) be credited with more behavior problems by their parents, and (v) show a smaller weight change after the end of the intervention compared to patients without eating disorder symptoms.

\section{Material and Methods}

\section{Sample Collection}

Between December 2007 and August 2008, a total of 67 patients (32 female; BMI $31.3 \pm 6.1 \mathrm{~kg} / \mathrm{m}^{2}$, age $12.5 \pm 2.6$ years) were examined at our obesity outpatient clinic. The inclusion criteria were either a BMI > 99.5th percentile or $>90$ th percentile plus at least one of the following metabolically relevant conditions: family history of type 2 diabetes mellitus, impaired glucose tolerance, or acanthosis nigricans. The subgroup chosen for the present analysis was aged $\geq 11$ years due to the minimum age for the self-report instruments applied (see below). Thus, out of the 67 patients, 41 patients ( 20 females, 21 males) were suitable for our investigation.

The time span between the two evaluations was $6 \pm 1$ months. After the lifestyle intervention, $97.6 \%$ (n $=40)$ of the participants were available for follow-up weight assessment and $82.3 \%(n=34)$ were available for follow-up assessment of eating disorder pathology. We performed a dropout analysis comparing the 7 participants not available for eating disorder pathology follow-up assessment with the remaining 34 participants with respect to all baseline characteristics displayed in table 1 as well as to the presence of eating disorder pathology and found no significant differences among the groups.

\section{Psychometric Instruments}

We used four validated and widely used questionnaires recommended by the German treatment guidelines for obesity in childhood and adolescence [21].

Child Behavior Checklist (CBCL)

The CBCL is a parent-report questionnaire assessing the parents' evaluation of their child's competencies and behavior problems [22]. We used a validated German version of the CBCL suitable for children and adolescents aged 4 to 18 years [23]. The CBCL comprises 118 items of behavioral problems covering nine different problem areas (e.g. anxious/depressed, attention problems, aggressive behavior) which can be evaluated 
from 0 (not true) to 2 (very true or very often true). Behavior problems are combined into three scales: internalizing problems (withdrawn, somatic complaints and anxious/depressive), externalizing problems (delinquent and aggressive behavior), and a total problem scale including all of the 118 items. We report on each of these scales. CBCL raw scores were transformed into T-scores adjusted for age and gender derived from a German normative sample [23] $(n=2,856)$, with high T-scores indicating more behavior problems. T-scores $\geq 63$ indicate clinically significant behavior problems, while T-scores slightly above 60 are considered as a threshold area for clinical significance. Reliability and validity of the CBCL has been demonstrated, including high internal consistency and independence of the subscales internalizing versus externalizing problems [24]. In our sample, we found a Cronbach's $\alpha=0.7$ for the subscale internalizing problems, a Cronbach's $\alpha=0.56$ for the subscale externalizing problems, and a Cronbach's $\alpha=0.9$ for the total problem scale.

Questionnaire for Measuring Health-Related Quality of Life in Children and Adolescents (KINDL)

The KINDL is a self-report questionnaire assessing HRQOL $[25,26]$. We used the two age-appropriate original German versions of the KINDL for the respective age groups (KID-KINDL of patients aged 11 years and KIDDO-KINDL for patients aged 12 to 17 years). The KINDL comprises 24 items covering six areas contributing to quality of life (physical well-being, emotional well-being, self-esteem, family, friends, and everyday functioning) which can be evaluated from 1 (never) to 5 (always) for the last week. We report the total quality of life score including all 24 items which is transformed into values between 0 and 100 , with high values indicating positive states. Good psychometric properties, including validity of the KINDL, have been demonstrated [25]. In our sample, we found a Cronbach's $\alpha=0.79$ for the total quality of life score. Normative data from a German representative sample with comparable age range are available [25].

\section{Rosenberg Self-Esteem Scale (RSES)}

The RSES is the most widely used self-report questionnaire for the assessment of global self-esteem [27]. It has been designed for adolescents [28]. We used a validated German version of the RSES [29] comprising 10 items which can be evaluated from 0 (not at all applicable) to 3 (fully applicable). The arithmetic mean of all 10 item raw scores reflects total self-esteem, with high values indicating higher self-esteem. Good psychometric properties, including satisfactory reliability and internal consistency of the RSES, have been demonstrated [27]. In our sample, we found a Cronbach's $\alpha=0.51$. No German normative data is available for adolescents.

\section{SCOFF}

The SCOFF is a brief self-report screening instrument assessing core symptoms of eating disorders [30, 31] which has been validated for the use in adolescents [32]. We employed a validated German version of the SCOFF suitable for adolescents aged 11 to 17 years [12]. The SCOFF comprises five questions that are answered with yes or no. Symptoms covered comprise pathogenic weight control behaviors, LOC over eating, rapid weight loss, body image disturbance, and preoccupation with food. Two questions answered with 'yes' are considered as the threshold for a positive screening for eating disorders. Cross-validation with clinical interviews has demonstrated a good validity of the SCOFF [30]. In our sample, we found a Cronbach's $\alpha=$ 0.64. As typical for screening instruments, the SCOFF has a very high sensitivity which is associated with a tendency to slightly overestimate true prevalence [33]. Data on SCOFF screening results is available from the representative German Health Interview and Examination Survey for Children and Adolescents [12].

\section{Lifestyle Intervention}

As reported in the literature, mean daily activity of a German schoolchild is about $1 \mathrm{~h}$ [34]. This report is consistent with our own clinical experience. In Germany, the concept of the 'optimized mixed diet' is officially recommended as a frame for dietary therapy of obese children and adolescents [21,35]. Therefore, the lifestyle intervention program consisted of (i) an increase in physical activity from 1 to $2 \mathrm{~h}$ per day including all activities of daily life and fitness training, plus a decrease of television viewing and excessive computer time to a total of $2 \mathrm{~h}$ or less; (ii) nutritional recommendations based on the 'Optimized Mixed Diet for German Children and Adolescents' of the Research Institute of Child Nutrition, Dortmund, Germany [35]; (iii) close surveillance by one physician (S.E.) [36]. We have used a low-threshold treatment program consisting of six sessions within 6 months focused on both the overweight youngsters and their parents. A standardized psychological component was not included. 
Fig. 1. SCOFF screening result in the study sample compared to a representative comparison sample. ${ }^{*}$ Data from the representative German Health Interview and Examination Survey for Children and Adolescents KIGGS, 2006 (N = 17,641).

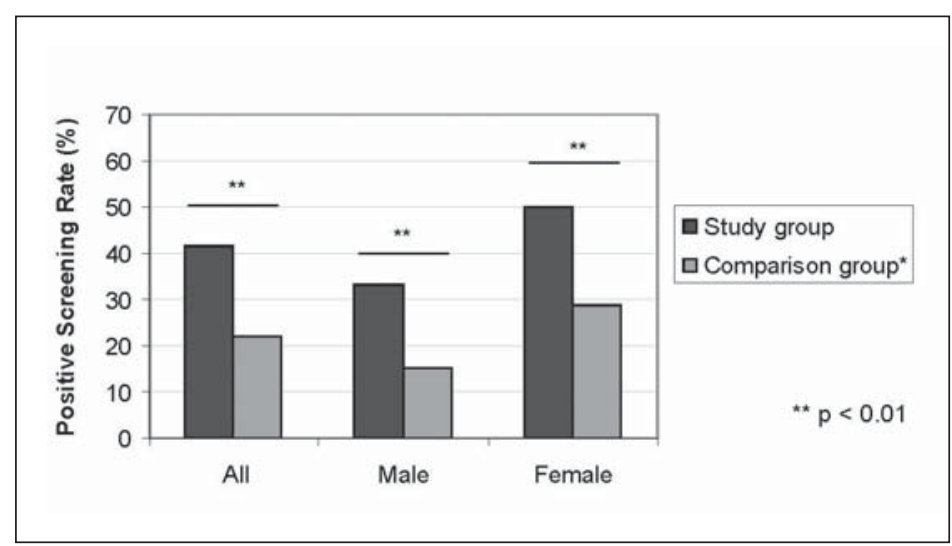

\section{Ethics Approval}

The ethics committee of the medical faculty of the University Tübingen approved the study. All parents gave their written informed consent.

\section{Statistical Analyses}

Data was analyzed using SPSS 19.0. Possible differences between data observed in the study sample and normative data were either analyzed using one-sample t-test for continuous data or chi-square test for categorical data. Possible cross-sectional differences between groups (e.g. patients with positive vs. negative screening result for an eating disorder) were analyzed using one-way analysis of variance for continuous data or chi-square test for categorical data. Overall weight change between baseline and end of intervention was analyzed using paired samples t-test. Possible group differences in weight change were analyzed using one-way analysis of covariance adjusting for baseline BMI-SDS $\mathrm{LMS}_{\mathrm{L}}$. A regression analysis was performed to examine the predictive value of a positive screening result for an eating disorder for weight change after the lifestyle intervention. Weight change expressed as $\triangle$ BMI-SDS $_{\mathrm{LMS}}$ was entered as dependent variable and the screening result was entered as independent variable.

\section{Results}

Sample

The patients' baseline characteristics were as shown in table 1. BMI-SDS ${ }_{\mathrm{LMS}}$ and fat mass were markedly increased. Compared to normative data, the study participants showed a significantly lower total quality of life $(\mathrm{t}(40)=-2.156 ; \mathrm{p}<0.05)$. Scores for internalizing and overall behavioral problems did not significantly differ from 60 as a threshold area for clinical significance $(\mathrm{t}(40)=1.48 ; \mathrm{p}>0.05$ and $\mathrm{t}(40)=0.405 ; \mathrm{p}>0.05)$.

\section{Eating Disorder Symptoms at Baseline}

As figure 1 displays, $41.5 \%$ of the study sample $(n=17)$ screened positively for an eating disorder. This rate was nearly twice as high as in a representative German sample of adolescents which covers all weight classes. Table 2 displays the prevalence of the respective eating disorder symptoms in the total sample and in this subgroup of 17 patients screened positively for an eating disorder. The symptom most often reported in both groups was worries about LOC over eating. Both female and male adolescents were equally affected by eating disorder 
Giel et al.: Eating Disorder Pathology in Adolescents Participating in a Lifestyle Intervention for Obesity: Associations with Weight Change, General Psychopathology ...

Table 2. Prevalence of eating disorder symptoms in the study sample at baseline as assessed by the SCOFF

\begin{tabular}{|c|c|c|c|c|c|c|}
\hline \multirow[t]{2}{*}{ Eating disorder symptom } & \multicolumn{3}{|c|}{ Total study sample $(n=41), \%$} & \multicolumn{3}{|c|}{$\begin{array}{l}\text { Subsample with positive SCOFF } \\
\text { screening result }(n=17), \%\end{array}$} \\
\hline & all & male & female & all & male & female \\
\hline Pathogenic weight-control behaviors & 0 & 0 & 0 & 0 & 0 & 0 \\
\hline LOC over eating & 51 & 43 & 57 & 94 & 100 & 91 \\
\hline Rapid weight loss & 5 & 5 & 5 & 11 & 14 & 9 \\
\hline Body image disturbance & 37 & 33 & 38 & 72 & 86 & 64 \\
\hline Preoccupation with food & 12 & 10 & 14 & 22 & 14 & 27 \\
\hline
\end{tabular}

Table 3. General psychopathology, HRQOL, and weight change in adolescents with positive compared to negative screening result for an eating disorder as assessed by the SCOFF

\begin{tabular}{|c|c|c|c|}
\hline \multirow[t]{2}{*}{ SCOFF screening result } & \multicolumn{3}{|l|}{ Mean \pm SD } \\
\hline & positive, $\mathrm{n}=17$ & negative, $n=24$ & $\mathrm{p}$ \\
\hline Internalizing problems ${ }^{\mathrm{a}}$ & $68.5 \pm 8.6$ & $59.2 \pm 9.6$ & $<0.01^{* *}$ \\
\hline Externalizing problems ${ }^{\mathrm{a}}$ & $61.8 \pm 8.7$ & $53.5 \pm 9.9$ & $0.02 *$ \\
\hline Total problem score ${ }^{a}$ & $64.5 \pm 11.5$ & $58.6 \pm 8.2$ & 0.08 \\
\hline Total quality of life $\mathrm{b}^{\mathrm{b}}$ & $67.9 \pm 8.9$ & $69.2 \pm 13.3$ & 0.719 \\
\hline Self-esteem ${ }^{c}$ & $2.4 \pm 0.4$ & $2.7 \pm 0.5$ & $0.01^{*}$ \\
\hline Weight change $\left(\Delta\right.$ BMI-SDS $_{\mathrm{LMS}}$ ) & $-0.9 \pm 0.1$ & $-1.0 \pm 0.2$ & 0.07 \\
\hline
\end{tabular}

${ }^{a}$ Assessed by the CBCL. ${ }^{b}$ Assessed by the KINDL. ${ }^{c}$ Assessed by the RSES. ${ }^{*} \mathrm{p}<0.05 .{ }^{* *} \mathrm{p}<0.01$.

symptoms. Adolescents with a positive screening result were comparable to those with a negative screening result concerning age, BMI-SDS ${ }_{\mathrm{LMS}}$, fat mass-SDS $\mathrm{LMS}_{\mathrm{LS}}$ and HOMA (homeostasis model assessment) index.

Table 3 compares data on general psychopathology and HRQOL at baseline in adolescents with positive versus negative screening result for an eating disorder. As indicated by their parents in the CBCL, three-fourths of adolescents with positive screening result for an eating disorder had clinically significant internalizing behavior problems - a significantly higher portion than in adolescents with negative screening result.

\section{Eating Disorder Symptoms and Weight Change}

Study participants showed a significant weight change by means of an average decrease of $0.1 \pm 0.2$ BMI-SDS ${ }_{\text {LMS }}(\mathrm{t}(39)=3.44 ; \mathrm{p}<0.01)$. Table 3 shows weight change in adolescents with positive versus negative screening result for an eating disorder. A positive screening for an eating disorder did not account for a significant proportion of variance of weight loss $\left(\mathrm{R}^{2}\right.$ $=3 \% ; \mathrm{F}(1,38)=0,03 ; \mathrm{p}>0.05)$.

$35 \%$ of the 34 patients at follow-up after the lifestyle intervention had a positive screening result for an eating disorder. This is comparable to baseline $\left(x^{2}(1)=0.533 ; p>0.05\right) .10$ adolescents ( $67 \%$ of the total sample) had a positive screening result for an eating disorder at both measurement points. 


\section{Discussion}

In the present study, we investigated eating disorder symptoms, general psychopathology, HRQOL, and weight change in obese adolescent patients participating in a lifestyle intervention lasting 6 months.

At baseline, the patients had a lower HRQOL than an age-matched normative sample. Their internalizing and overall behavior problems scored in the threshold area for clinical significance (T-score $>60$ ). At baseline, $42 \%$ of patients were screened positive for an eating disorder, and this subgroup reported lower self-esteem and had more behavior problems than the subgroup unaffected by eating disorder pathology.

The screening rate of eating disorder symptoms in our sample was nearly twice as high as in an age-matched normative sample [12]. Nearly all patients with a positive screening result reported worries about LOC over eating. It is important to note that only a part of our sample might indeed experience actual LOC over eating. As only few studies on pediatric obesity report on eating pathology, it is difficult to appraise the relatively high prevalence in our sample with respect to other clinical populations. Our patients belong to a referred group with severe overweight, and eating disorder pathology has been found to be considerably higher in referred compared to non-referred overweight adolescents [37]. Additionally, it should be considered that we used a screening instrument to assess eating disorder pathology, and this has a tendency to slightly overestimate true prevalence [33].

The patients treated in our study showed increased behavior problems and an impaired HRQOL which has also been described by earlier studies in obese adolescents (see [20] for a review). The subgroup of patients with positive screening result for an eating disorder was characterized by an even increased psychopathological burden, including lower self-esteem and increased behavior problems. This finding matches evidence from both the general population and clinical groups $[12,38]$, while at the same time, it is important to consider that we do not have additional data from expert ratings to complement self-report data.

According to earlier evidence on the relationship of obesity, psychopathology, and quality of life, the psychopathological burden identified in our sample might partly reflect a contributing and partly a maintaining factor of overweight, while impaired HRQOL might in turn be a consequence of increased psychopathology [20,39, 40].

While the patients on the whole reduced their overweight after the intervention significantly, prevalence of eating disorder symptoms remained stable. Weight change was unaffected by eating disorder pathology. The intervention success with respect to weight loss is considered a very positive result as the sample consisted of severely obese adolescents vulnerable to multiple sequelae of overweight. The successful weight change in patients with eating pathology is especially remarkable as eating disorder symptoms have been identified as a negative predictor of treatment success in an inpatient weight-loss intervention for children and adolescents [18].

Patients screened positive for eating disorder pathology did not benefit from the lifestyle intervention with respect to eating pathology. As the lifestyle intervention did not specifically target eating disorder symptoms, this finding is not surprising and is in line with recent evidence for a high persistence of eating pathology in untreated obese pediatric samples [41]. However, several earlier treatment trials report that pediatric weight-loss interventions also resulted in a reduction of eating pathology (see [8] for a review). When interpreting our finding, it has to be taken into account that we used a screening instrument to assess eating pathology, and this could have been lacking sensitivity to change.

A limitation of our study is that all instruments were based on self- or parent-report and no expert rating, e.g. via semi-structured clinical interviews, was assessed. This is especially critical with respect to the assessment of eating pathology as information from question- 
Giel et al.: Eating Disorder Pathology in Adolescents Participating in a Lifestyle

naires has been found to result in a higher reported pathology compared to information from expert interviews [42]. Moreover, children and adolescents seem to have problems to selfreport a more complex eating pathology in questionnaires [42]. The results on eating disorder symptoms are based on a screening instrument and are therefore prone to overestimation or misclassification [43]. A recruitment bias might constrain the generalizability of our findings. Adolescents seeking help for obesity in a specialized academic outpatient department might present with more severe impairments than a group of treatment-seeking patients from the general community.

Taken together, we identified a high proportion of adolescent obese patients participating in a lifestyle intervention for weight loss that screened positively for an eating disorder and is characterized by an increased psychopathological burden but does not show an impaired HRQOL compared to patients unaffected by eating disorder symptoms. While these patients profited from the weight-loss intervention with respect to weight loss, eating disorder pathology proved to be stable.

Our results emphasize the importance of the assessment of information related to eating disorder pathology as well as general psychopathological and psychosocial functioning by health care providers in pediatric obesity, as already stated by other authors $[8,13,20]$. A second implication of our results is the need for an integrated view on eating and weight problems in children and adolescents in prevention and treatment approaches - due to the large overlap, mutual interaction, and high burden of both conditions [8]. For example, this includes the integration of psychosocial and behavioral interventions into weight loss treatment, especially for vulnerable subgroups.

\section{DISKUS Study Group}

Perikles Simon, Sports Medicine, Gutenberg University, Mainz, Germany; Andre Lacroix, Jochen Hansel, Andreas Nieß, Sports Medicine, University Hospital for Internal Medicine, Tuebingen, Germany; Markus Schrauth ${ }^{\dagger}$, Paul Enck, Stephan Zipfel, Department of Psychosomatic Medicine and Psychotherapy, University Hospital for Internal Medicine, Tuebingen, Germany; Jürgen Machmann, Fabian Springer, Verena Ballweg, Fritz Schick, Section on Experimental Radiology, Department of Diagnostic Radiology, Eberhard-KarlsUniversity, Tuebingen, Germany; Michael S. Urschitz, Department of Neonatology, University Children's Hospital, Tuebingen, Germany; Andreas Neu, Hans Peter Haber, Coya Pfaff, Nicole Schurr, Department of Paediatrics, University Children's Hospital, Tuebingen, Germany; Huu Phuc Nguyen, Department of Medical Genetics, Eberhard-Karls-University, Tuebingen, Germany.

\section{Acknowledgments}

This study was supported by a research grant from the Tuebingen University Hospital (AKF-Program, nr. 221-2-0).

\section{Disclosure Statement}

None of the authors declares a conflict of interest. 
Giel et al.: Eating Disorder Pathology in Adolescents Participating in a Lifestyle Intervention for Obesity: Associations with Weight Change, General Psychopathology ...

\section{References}

1 Oude Luttikhuis H, Baur L, Jansen H, Shrewsbury VA, O'Malley C, Stolk RP, Summerbell CD: Interventions for treating obesity in children. Cochrane Database Syst Rev 2009;(1):CD001872.

-2 Tsiros MD, Olds T, Buckley JD, Grimshaw P, Brennan L, Walkley J, Hills AP, Howe PRC, Coates AM: Healthrelated quality of life in obese children and adolescents. Int J Obes (Lond) 2009;33:387-400.

-3 Griffiths LJ, Parsons TJ, Hill AJ: Self-esteem and quality of life in obese children and adolescents: a systematic review. Int J Pediatr Obes 2010;5:282-304.

4 Fontaine KR, Barofsky I: Obesity and health-related quality of life. Obes Rev 2001;2:173-182.

5 Lowry K, Sallinen B, Janicke D: The effects of weight management programs on self-esteem in pediatric overweight populations. J Pediatr Psychol 2007;32:1179-1195.

-6 Rosenberger PH, Henderson KE, Grilo CM: Psychiatric disorder comorbidity and association with eating disorders in bariatric surgery patients: a cross-sectional study using structured interview-based diagnosis. J Clin Psychiatry 2006;67:1080-1085.

7 Villarejo C, Fernandez-Aranda F, Jimenez-Murcia S, Penas-Lledo E, Granero R, Penelo E, Tinahones FJ, Sancho C, Vilarrasa N, Montserrat-Gil de Bernabe M, Casanueva FF, Fernandez-Real JM, Fruhbeck G, De la Torre R, Treasure J, Botella C, Menchon JM: Lifetime obesity in patients with eating disorders: increasing prevalence, clinical and personality correlates. Eur Eat Disord Rev 2012;20:250-254.

-8 Goldschmidt AB, Aspen VP, Sinton MM, Tanofsky-Kraff M, Wilfley DE: Disordered eating attitudes and behaviors in overweight youth. Obesity (Silver Spring) 2008;16:257-264.

-9 Goossens L, Braet C, Van Vlierberghe L, Mels S: Weight parameters and pathological eating as predictors of obesity treatment outcome in children and adolescents. Eat Behav 2009;10:71-73.

10 Decaluwé V, Braet C, Fairburn CG: Binge eating in obese children and adolescents. Int J Eat Disord 2003;33: 78-84.

11 Doyle AC, le Grange D, Goldschmidt A, Wilfley DE: Psychosocial and physical impairment in overweight adolescents at high risk for eating disorders. Obesity (Silver Spring) 2007;15:145-154.

12 Hölling H, Schlack R: Essstörungen im Kindes- und Jugendalter. Bundesgesundheitsbl Gesundheitsforsch Gesundheitsschutz 2007;50:794-799.

13 Vila G, Zipper E, Dabbas M, Bertrand C, Robert JJ, Ricour C, Mouren-Siméoni MC: Mental disorders in obese children and adolescents. Psychosom Med 2004;66:387-394.

14 Crow S, Eisenberg ME, Story M, Neumark-Sztainer D: Psychosocial and behavioral correlates of dieting among overweight and non-overweight adolescents. J Adolesc Health 2006;38:569-574.

15 Hudson J, Hiripi E, Pope HJ, Kessler R: The prevalence and correlates of eating disorders in the national comorbidity survey replication. Biol Psychiatry 2007;61:348-358.

-16 Kotler LA, Cohen P, Davies M, Pine DS, Walsh BT: Longitudinal relationships between childhood, adolescent, and adult eating disorders. J Am Acad Child Adolesc Psychiatry 2001;40:1434-1440.

17 Neumark-Sztainer D, Wall M, Guo J, Story M, Haines J, Eisenberg M: Obesity, disordered eating, and eating disorders in a longitudinal study of adolescents: how do dieters fare 5 years later? J Am Diet Assoc 2006; 106: 559-568.

18 Braet C: Patient characteristics as predictors of weight loss after an obesity treatment for children. Obesity (Silver Spring) 2006;14:148-155.

19 Eddy KT, Tanofsky-Kraff M, Thompson-Brenner H, Herzog DB, Brown TA, Ludwig DS: Eating disorder pathology among overweight treatment-seeking youth: clinical correlates and cross-sectional risk modeling. Behav Res Ther 2007;45:2360-2371.

20 Hebebrand J, Herpertz-Dahlmann B: Psychological and psychiatric aspects of pediatric obesity. Child Adolesc Psychiatr Clin N Am 2009;18:49-65.

21 Arbeitsgemeinschaft Adipositas im Kindes- und Jungendalter (AGA): Leitlinie Diagnostik, Therapie und Prävention von Übergewicht und Adipositas im Kindes- und Jugendalter. München, AGA, 2010.

22 Achenbach T: Manual for the Child Behavior Checklist/4-18 and 1991 profile. Burlington, Department of Psychiatry, University of Vermont, 1991.

23 Arbeitsgruppe Deutsche Child Behavior Checklist: Elternfragebogen über das Verhalten von Kindern und Jugendlichen. Deutsche Bearbeitung der Child Behavior Checklist (CBCL/4-18). Einführung und Anleitung zur Handauswertung. Köln, Arbeitsgruppe Kinder-, Jugend- und Familiendiagnostik, 1998.

24 Döpfner M, Schmeck K, Berner W: Handbuch: Elternfragebogen über das Verhalten von Kindern und Jugendlichen. Forschungsergebnisse zur deutschen Fassung der Child Behavior Checklist (CBCL). Köln, Arbeitsgruppe Kinder-, Jugend- und Familiendiagnostik, 1994.

25 Ravens-Sieberer U, Ellert U, Erhart M: Gesundheitsbezogene Lebensqualität von Kindern und Jugendlichen in Deutschland. Eine Normstichprobe für Deutschland aus dem Kinder- und Jugendgesundheitssurvey (KIGGS). Bundesgesundheitsbl Gesundheitsforsch Gesundheitsschutz 2007;50:810-818.

26 Ravens-Sieberer U: Der KINDL-R-Fragebogen zur Erfassung der gesundheitsbezogenen Lebensqualität bei Kindern und Jugendlichen - revidierte Form; in Schumacher JKA, Brähler E (eds): Diagnostische Verfahren zu Lebensqualität und Wohlbefinden. Göttingen, Hogrefe, 2003, pp 184-188.

27 Roth M, Decker O, Herzberg PY, Brähler E: Dimensionality and norms of the Rosenberg Self-Esteem Scale in a German general population sample. Eur J Psychol Assess 2008;24:190-197.

28 Rosenberg M: Society and the adolescent self-image. Princeton, NJ, Princeton University Press, 1965. 
Giel et al.: Eating Disorder Pathology in Adolescents Participating in a Lifestyle Intervention for Obesity: Associations with Weight Change, General Psychopathology ...

29 von Collani G, Herzberg PY: Eine revidierte Fassung der deutschsprachigen Skala zum Selbstwertgefühl von Rosenberg. Z Diff Diagn Psychol 2003;24:3-7.

30 Hill LS, Reid F, Morgan JF, Lacey JH: SCOFF - the development of an eating disorder screening questionnaire. Int J Eat Disord 2010;43:344-351.

31 Morgan JF, Reid F, Lacey JH: The SCOFF questionnaire: assessment of a new screening tool for eating disorders. BMJ 1999;319:1467-1468.

-32 Rueda G, Diaz L, Ortif D, Prinzon C, Rodriguez J, Cadena L: Validation of the SCOFF questionnaire for screening of eating behaviour disorders of adolescents in school. Aten Primaria 2005;15:89-94.

-33 Luck AJ, Morgan JF, Reid F, O’Brien A, Brunton J, Price C, Perry L, Lacey JH: The SCOFF questionnaire and clinical interview for eating disorders in general practice: comparative study. BMJ 2002;325:755-756.

34 Obst F, Bös K: Akzeptanz und Wirkung zusätzlicher Sportstunden in der Grundschule. Sportpraxis 1997;2: 44-48.

35 Kersting M, Alexy U, Clausen K: Using the concept of food based dietary guidelines to develop an optimized mixed diet (OMD) for German children and adolescents. J Pediatr Gastroenterol Nutr 2005;40:301-308.

36 Ehehalt S, Schweizer R, Blumenstock G, Pfaff C, Schurr N, Weber K, Ranke MB, Binder G: Investigation of myostatin serum levels before and after a 6-month lifestyle intervention program in obese children. Exp Clin Endocrinol Diabetes 2011;119:238-242.

-37 Van Vlierberghe L, Braet C, Goossens L, Mels S: Psychiatric disorders and symptom severity in referred versus non-referred overweight children and adolescents. Eur Child Adolesc Psychiatry 2009;18:164-173.

38 Halfon N, Larson K, Slusser W: Associations between obesity and comorbid mental health, developmental, and physical health conditions in a nationally representative sample of US children aged 10 to 17. Acad Pediatr 2013;13:6-13.

-39 Ravens-Sieberer U, Redegeld M, Bullinger M: Quality of life after in-patient rehabilitation in children with obesity. Int J Obes Relat Metab Disord 2001;25(suppl 1):S63-65.

40 Zeller M, Kirk S, Claytor R, Khoury P, Grieme J, Santangelo M, Daniels S: Predictors of attrition from a pediatric weight management program. J Pediatr 2004;144:466-470.

-41 Tanofsky-Kraff M, Shomaker L, Olsen C, Roza C, Wolkoff L, Columbo K, Raciti G, Zocca J, Wilfley D, Yanovski S, Yanovski J: A prospective study of pediatric loss of control eating and psychological outcomes. J Abnorm Psychol 2011;120:108-118.

-42 Decaluwé V, Braet C: Assessment of eating disorder psychopathology in obese children and adolescents: interview versus self-report questionnaire. Behav Res Ther 2004;42:799-811.

43 Ricca V, Mannucci E, Moretti S, Di Bernardo M, Zucchi T, Cabras PL, Rotella CM: Screening for binge eating disorder in obese outpatients. Compr Psychiatry 2000;41:111-115. 